\title{
Morfología polínica de Staelia S.L. (RubiaceAe)
}

\author{
ROBERTO M. SALAS ${ }^{1,2}$ y ELSA L. CABRAL ${ }^{1}$
}

\begin{abstract}
Summary: Pollen morphology of Staelia s.I. (Rubiaceae). This paper deals the study of the pollen grains of Staelia s.I. Currently, it have been studied only four of 25 species of this taxon. We carried out an analysis of the pollen morphology of all species belonging to the four genera of Staelia s.I.: Anthospermopsis, Planaltina, Tessiera and Staelia s.s. As result, we found a remarkable homogeneity of pollinic characters within each genus, which is evidenced in a single pollen type for each taxon, except for Anthospermopsis. Tessiera and Planaltina are differentiated from Staelia by the pollen size $(P=42-75, E=50-78.4$ vs. $P=21-34, E=20-30.8 \mu \mathrm{m})$ and length of colpi $(L C / P=0.22-0.31$ vs. $L C / P=0.57-0.77 \mu \mathrm{m})$, whereas the pollen of Anthospermopsis is virtually indistinguishable from the remaining species of Staelia. Furthermore, the three pollen types are very similar to those stated for African and Australian Spermacoce species. The pollinic type of Staelia is also shared with the monospecific genus Emmeorhiza. For these reasons, we proposed to extend the classification of the pollen types previously described for Borreria and Spermacoce (designated by Arabic numbers, 1-20) to the genera studied here. The pollen grains are described and illustrated by images of scanning electron microscope. The lower surface of the nexine is described through broken grains.
\end{abstract}

Keys word: Anthospermopsis, multiaperturate, Planaltina, pollen, Spermacoceae, Tessiera.

Resumen: Este trabajo trata el estudio de los granos de polen de Staelia s.l. Actualmente, es un grupo escasamente estudiado en este aspecto, ya que solo se describieron cuatro de 25 especies. Se estudió el polen de todas las especies de Anthospermopsis, Planaltina, Tessiera y Staelia s.s. Como resultado, se encontró una notable homogeneidad de caracteres polínicos dentro de cada género, que se pone de manifiesto en un único tipo de polen para cada taxón, excepto para Anthospermopsis. Tessiera y Planaltina se diferencian de Staelia por el tamaño de los granos ( $\mathrm{P}=42-75$ y $E=50-78,4$ vs. $\mathrm{P}=21-34$ y $\mathrm{E}=20-30,8 \mu \mathrm{m}$ ) y longitud de los colpos ( $\mathrm{LC} / \mathrm{P}=0,22-0,31 \mathrm{vs}$. 0,57-0,77 $\mu \mathrm{m})$, mientras que Anthospermopsis es prácticamente indistinguible de las otras especies de Staelia. Además, los tres tipos polínicos son similares a los establecidos para especies de Spermacoce de África y Australia. El tipo polínico de Staelia también es compartido con Emmeorhiza. Por estas razones, se propone incorporar a la clasificación de los tipos polínicos descritos anteriormente para Borreria y Spermacoce (designados con números arábigos, del 1-20) a los géneros aquí estudiados. Los tres tipos polínicos son descritos e ilustrados mediante imágenes de microscopio electrónico de barrido. El interior de la nexina es también analizada a partir de granos rotos.

Palabras clave: Anthospermopsis, multiaperturado, Planaltina, polen, Spermacoceae, Tessiera.

\section{INTRODUCCIÓN}

El género Staelia fue descripto por Chamisso \& Schlechtendal (1828) sobre una especie del sur de Brasil, S. thymoides Cham. \& Schltdl. En 1888, Schumann realizó el primer estudio

\footnotetext{
${ }^{1}$ Instituto de Botánica del Nordeste, Facultad de Ciencias Exactas y Naturales y Agrimensura, UNNE. Corrientes. E-mail: robertoymanuels@gmail.com. ${ }^{2}$ Parte de los resultados de la tesis doctoral del primer autor.
}

integral del género. El autor propuso agrupar a las especies de Brasil en tres secciones [Staelia secc. Anthospermopsis K. Schum, secc. Tessiera (DC.) K. Schum. y secc. Staelia]. En esta clasificación, subordinó al género afín Tessiera DC., previamente descrito por Candolle (1830) con dos especies T. lanigera DC. y T. lithospermoides DC. Posteriormente, otros autores incorporaron o segregaron de Staelia a otros taxones, Diphragmus 
C. Presl fue reducido a sinónimo por Standley (1931) y Staelia secc. Anthospermopsis K. Schum. fue separada por Kirkbride (1997) como un género aparte, Anthospermopsis (K. Schum) J.H. Kirkbr. Este último, permanece actualmente como género válido basado en el tipo único de dehiscencia del fruto, ya que no se han realizado estudios posteriores probablemente debido a su distribución restringida.

De acuerdo a Andersson (1992), Staelia consta de 14 especies distribuidas desde México hasta Argentina y Uruguay. En este género fueron incluidas especies morfológicamente diferentes que no se correspondían con la especie tipo, por lo cual, este grupo de especies fue considerado un taxón artificial y denominado Staelia s.l. (Salas, 2012). Los principales aportes en este grupo fueron llevados a cabo en los últimos años por Salas \& Cabral (2006a, b; 2010a, b; 2011a, b; 2012a, b). En cuanto a la delimitación de este grupo, Salas \& Cabral (2010a, b) propusieron los siguientes cambios: 1) rehabilitar Tessiera al estatus genérico y lectotipificarlo en base a la especie mexicana, T. lithospermoides, bajo este género se subordinó a Diphragmus; 2) describir al nuevo género denominado Planaltina R.M. Salas \& E.L. Cabral constituido por tres especies exclusivamente brasileñas (incluida la especie brasileña de Tessiera); 3) delimitar Staelia s.s., manteniendo aquí a todas las especies que presentan la dehiscencia del fruto similar a la especie tipo. Bajo esta circunscripción Staelia está representado por 18 especies distribuidas en Argentina, Bolivia, Brasil, Paraguay y Uruguay.

\section{Antecedentes palinológicos}

El grano de polen más basal y común dentro de la familia Rubiaceae es 3-colporado, sin embargo, en muchas tribus este carácter se presenta notablemente modificado (Dessein et al., 2005b). En Spermacoceae, los primeros trabajos fueron realizados en el marco de estudios filogenéticos amplios (e.g. Bremekamp, 1952; Verdcourt, 1958), en los que se reportó al polen multiaperturado como el más común. De acuerdo a Dessein et al., (2005b), este tipo de polen representa una condición derivada propia de los linajes herbáceos de Rubiáceas, tales como Rubieae y Spermacoceae. En este último taxón, el número de aberturas varía de 3 a 25 (Dessein et al., 2002). Trabajos polínicos recientes sentaron precedentes en cuanto al valor sistemático del polen en la tribu. Fue utilizado para sustentar rangos genéricos (Galianthe Griseb.: Cabral, 1991; Pire \& Cabral, 1992; Pire, 1997; Denscantia E.L. Cabral \& Bacigalupo: Cabral \& Bacigalupo, 2001a, b), clasificaciones infragenéricas (secciones de Psyllocarpus Mart. \& Zucc.: Kirkbride, 1979; subdivisión de Borreria: Cabral, 1985; Bacigalupo \& Cabral, 1996; Pire, 1996) y diferenciar especies (Spermacoce L.: Dessein et al., 2003). Dessein et al., (2002, 2005a) describieron en especies africanas y australianas de Spermacoce a 21 tipos polínicos, de los cuales 11 son compartidos con especies de Borreria (Pire, 1997), 9 son exclusivos de África o Australia y 2 se desconocían en Angiospermas.

En Mitracarpus Zucc. ex Zucc. \& Schult.f se describieron 6 tipos polínicos que además presentaron cierta correlación con caracteres seminales (Souza, 2008).

En cuanto a Staelia s.l. se conocen escasos aportes, siendo el primer dato polínico una descripción muy somera realizada por Schumann (1888). El polen de Staelia thymoides fue estudiado por Galati (1988), quien lo describió como 10-colporado, con colpos largos y tectum perforado. La autora mencionó que algunos de estos caracteres se observan en 2 especies de Mitracarpus por ella analizadas, $M$. hirtus (Sw.) DC. y M. megapotamicus (Spreng.) Kuntze.

Pire (1993), realizó una presentación preliminar de los tipos polínicos en la tribu Spermacoceae y ubicó a Staelia (basado en Staelia thymoides) dentro del tipo 2, "Borreria", por presentar tectum perforado y ser uniformemente espinulado, y dentro de éste en el subtipo 2c "Borreria umbellata" [=Emmeorhiza umbellata (Spreng.) K. Schum.] por presentar colpos largos. Dessein (2003), realizó una descripción polínica de Staelia basada en S. virgata (Link ex Roem. \& Schult.) K. Schum. y S. capitata (=Planaltina capitata), lo que resultó en dos tipos polínicos bien marcados, uno con colpos cortos y granos grandes (grupo Staelia capitata) y otro con colpos largos y granos medianos a pequeños (grupo Staelia thymoides). Salas \& Cabral (2010a, b) rehabilitaron al género Tessiera y segregaron a Planaltina de los límites de Staelia, basado entre otros caracteres, en los aportes palinológicos. A nivel específico, Salas \& Cabral (2010c) analizaron 3 especies paraguayas y concluyeron que los caracteres polínicos son notoriamente uniformes. Por otro lado, el polen 


\section{R. M. Salas y E. L. Cabral - Morfología polínica de Staelia s.I. (Rubiaceae)}

sirvió como soporte en la descripción de la nueva especie Staelia catolensis R.M. Salas \& E.L. Cabral (Salas \& Cabral, 2012a). Recientemente, Silveira et al., (2012) describieron el polen de 2 especies de Staelia basados en microscopia óptica y para una región geográfica específica de Bahia, Brasil.

En cuanto a Anthospermopsis y Tessiera no se encontraron referencias en la literatura relacionadas con la morfología polínica, probablemente por el escaso conocimiento taxonómico del grupo. Los objetivos de este trabajo son (1) caracterizar la morfología polínica de las especies de los géneros segregados de Staelia s.l. y (2) discutir su aplicación para diferenciarlos entre sí y de otros géneros de Rubiaceae.

\section{MATERIALES Y MÉtodos}

La determinación de la morfología del polen se realizó con microscopio óptico (MO) y con microscopio electrónico de barrido (MEB). La preparación del material se llevó a cabo siguiendo la técnica de acetólisis sugerida por Erdtman (1966). Se utilizó gelatina-glicerinada como medio de montaje para el microscopio óptico. Para la observación con microscopio electrónico de barrido (MEB), los granos acetolizados se deshidrataron en series crecientes de alcoholes $(50,70,90$ y $100 \%)$, luego se montaron en película fotográfica y se metalizaron con oro-paladio. Se utilizó la terminología de Punt et al., (2007) y de Dessein et al., $(2002,2005 b)$ para la descripción de los granos de polen. Las descripciones se basaron en las mediciones de un mínimo de 20 granos. Los materiales analizados se resumen en el apéndice.

\section{Resultados}

A continuación se describen los 3 tipos polínicos resaltando los casos más puntuales dentro de cada género: Tipos Planaltina, Staelia y Tessiera.

\section{Planaltina}

MO - Los granos de polen son 10-11 (-13) estefanocolporados, suboblatos a oblato- esferoidales, radiosimétricos, isopolares y de ámbito circular. Tamaño grande, los valores de los diámetros son $\mathrm{P}=42-65 \mu \mathrm{m}$ y $\mathrm{E}=50-64,5 \mu \mathrm{m}$. Colpos cortos de 12,5-14,8 $\mu \mathrm{m}(\mathrm{LC} / \mathrm{P}=0,22-0,29)$, endoaberturas en endocíngulo, de 10,3-11,8 $\mu \mathrm{m}$, con márgenes difusos. Exina de 3-5 $\mu \mathrm{m}$, sexina mayor o igual que la nexina, las columelas no varían de tamaño entre meso y apocolpio (Fig. 1 D-F).

MEB - Dos tipos de esculturas fueron encontradas en Planaltina, una microreticuladareticulada $[P$. capitata (Fig. $1 \mathrm{~A}, \mathrm{C})]$ y la otra perforada-microreticulada $[P$. myndeliana (Fig. 1 G-H) y P. lanigera (Fig. $1 \mathrm{I}-\mathrm{K})]$. En el primer tipo se encontraron lúmenes de 0,5 a $2,4 \mu \mathrm{m}$ y muros de $0,3-0,5 \mu \mathrm{m}$. El segundo tipo presenta lúmenes de $0,1-1,05 \mu \mathrm{m}$ y muros $0,3-0,5 \mu \mathrm{m}$ de espesor. Las perforaciones son subcirculares o alargadas, su densidad no varía entre meso o apocolpio. Como carácter distintivo las perforaciones o lúmenes presentan bordes espesados (Fig.1 C, H, K). Las microespinas son $0,4-0,5 \mu \mathrm{m}$ de altura y $0,9-1,2 \mu \mathrm{m}$ de base, las cuales se encuentran uniformemente distribuidas (Fig. 1 A, C, G-L). La densidad de las espínulas no varía entre meso y apocolpio. En granos rotos se observó que la exina es de 3,2-4,16 $\mu \mathrm{m}$ de espesor, la sexina de 1,8-2,1 (tectum de $0,8-0,95$ y columelas de $1-1,1 \mu \mathrm{m}$ ) y la nexina de $1,8-2,8 \mu \mathrm{m}$. Interior de la nexina aparentemente granular (Fig. 1 B).

\section{Staelia (incluido Anthospermopsis)}

MO - Las especies estudiadas son muy homogéneas desde el punto de vista palinológico (Fig. 2-5). Los granos son 7-10 estefanocolporados, esferoidales, raro suboblatos, radiosimétricos, isopolares y de ámbito circular. Tamaño pequeño a mediano, los valores de $\mathrm{P}$ y E varían entre 21$34 \mu \mathrm{m}$ y $20-30,8 \mu \mathrm{m}$ respectivamente. Colpos largos de $12-21,7 \mu \mathrm{m}$ de longitud $(\mathrm{LC} / \mathrm{PC}=0,57$ $0,77)$ y endoaberturas en endocíngulo $(3-5 \mu \mathrm{m})$ con extensiones hasta 5-7 $\mu \mathrm{m}$ a nivel de los colpos, márgenes difusos. Exina de 2,2-3,5 $\mu \mathrm{m}$ de espesor, siendo la sexina igual o más gruesa que la nexina, las columelas no varían de tamaño entre meso y apocolpio. Exina tectado-perforada o microreticulada, microequinada (Fig. 2, 3, 4, 5).

MEB - La exina es en la mayoría de los casos tectado-perforada (Fig. 3 B-C, F-G; 4 C-D, G; 5 C-D, G-H, K-L), solo Staelia catolensis presenta 
Bol. Soc. Argent. Bot. 49 (1) 2014
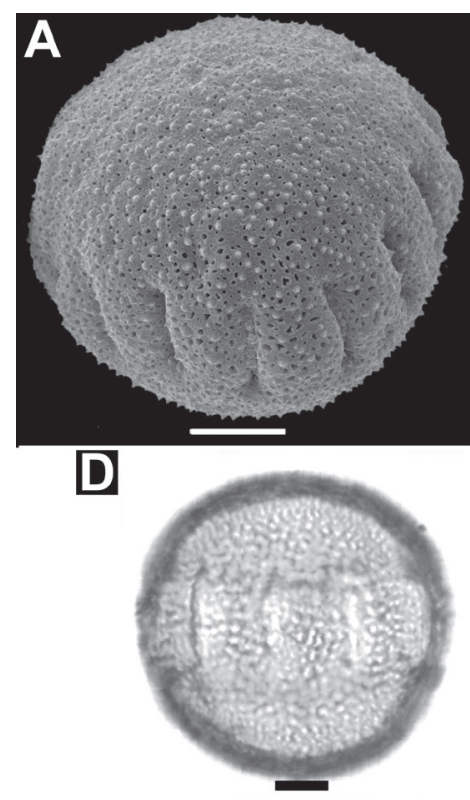

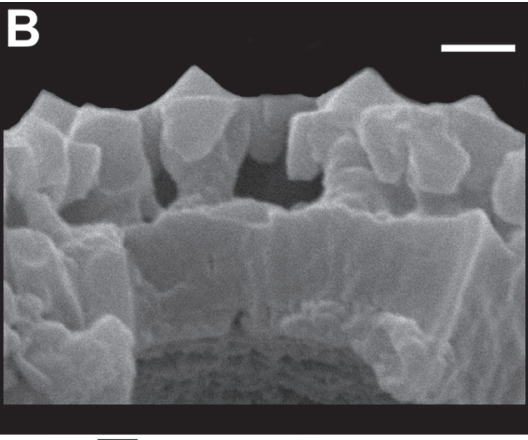

目

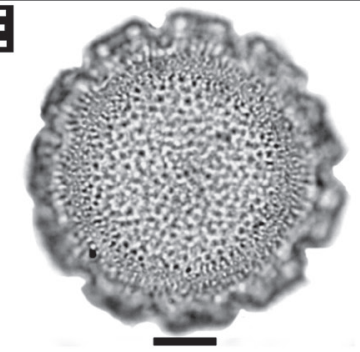

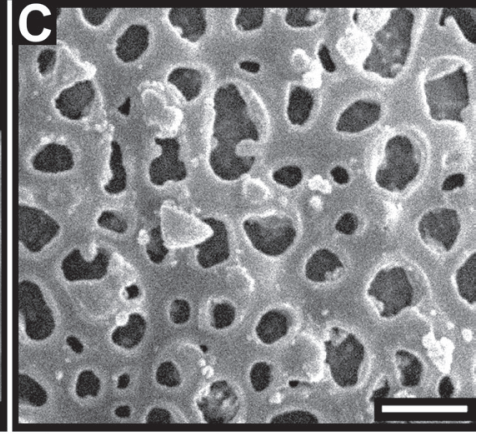

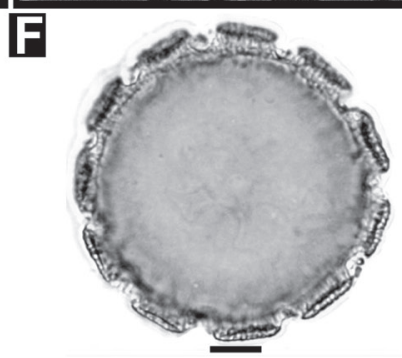

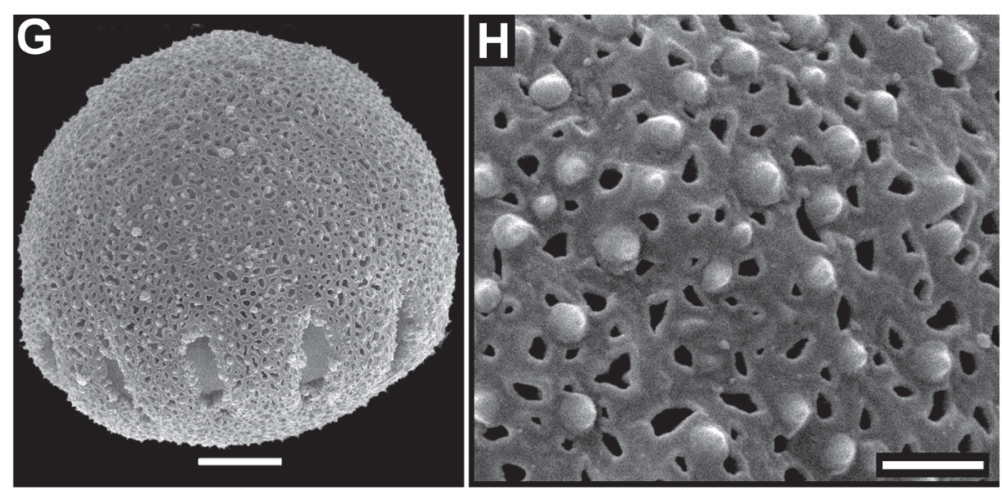
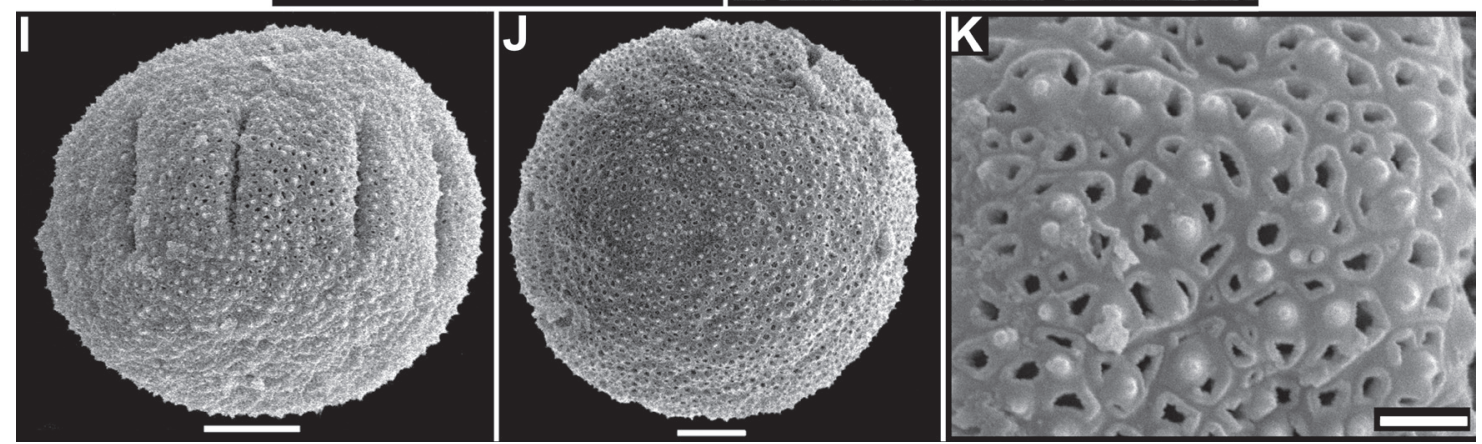

Fig. 1. Microfotografías de Polen de Planaltina. A-F: Planaltina capitata A: Vista subpolar de grano de polen. B: Exina en un grano roto. C: Detalle de exina con perforaciones y lúmenes intercalados. D: Vista ecuatorial en foco inferior con el área del endocíngulo más clara (MO). E: Vista polar de grano 11-zonocolporado (MO). F: Corte óptico de grano de polen. G-H: Planaltina lanigera. G: Vista subpolar. H: Detalle de exina con perforaciones y lúmenes irregulares, intercalados. I-K: Planaltina myndeliana. I: Vista ecuatorial. J: Vista polar. K: Detalle de exina. A-F: Hatschbach G. \& J.M. Silva 60036 (CTES). G-I: Hatschbach M. et al. 64238 (CTES). J-K: Hatschbach G. \& J.M. Silva 60266 (CTES). Escalas A, D-F, G-H, J-K=10 $\mu \mathrm{m}, \mathrm{B}-\mathrm{C}, \mathrm{I}, \mathrm{L}=2 \mu \mathrm{m}$. 
R. M. Salas y E. L. Cabral - Morfología polínica de Staelia s.I. (Rubiaceae)
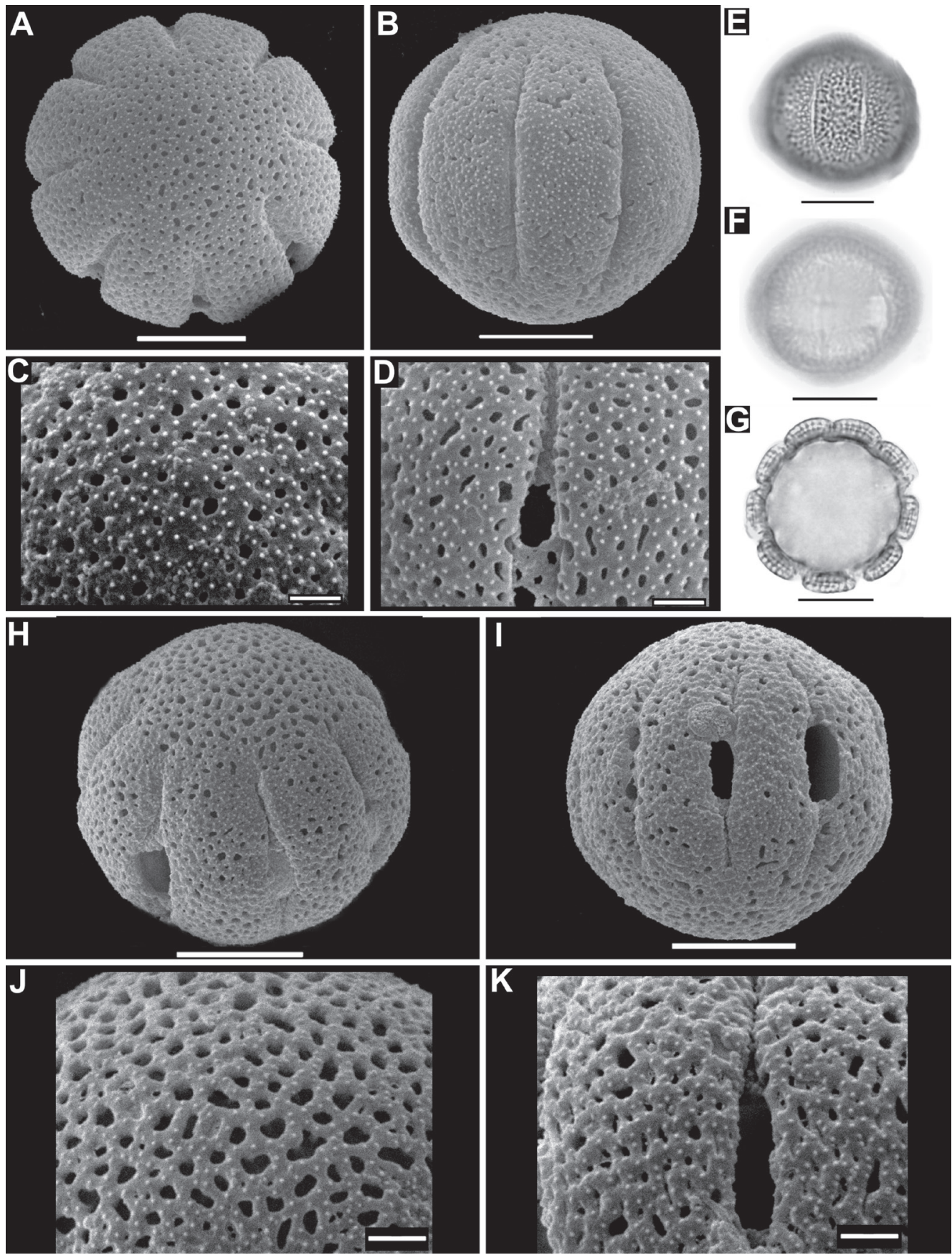

Fig. 2. Microfotografías de polen de Anthospermopsis y Staelia. A-G: Anthospermopsis catechosperma. A: Vista polar de grano de polen. B: Vista ecuatorial de grano de polen. C: Detalle del apocolpio. D: Detalle del mesocolpio. E: Vista ecuatorial en foco superior (MO). F: Vista ecuatorial en foco inferior donde se evidencia el endocíngulo (MO). G: Corte óptico de grano de polen (MO). H-K: Staelia catolensis. H: Vista subpolar. I: Vista ecuatorial. J: Detalle de apocolpio. K. Detalle de mesocolpio. A-G: R.M. Salas \& al. 438 (CTES). H-K: W. Ganev 519 (HUEFS). Escalas A-B, E-G, H-I=10 $\mu \mathrm{m}, \mathrm{C}-\mathrm{D}, \mathrm{J}-\mathrm{K}=2 \mu \mathrm{m}$. 

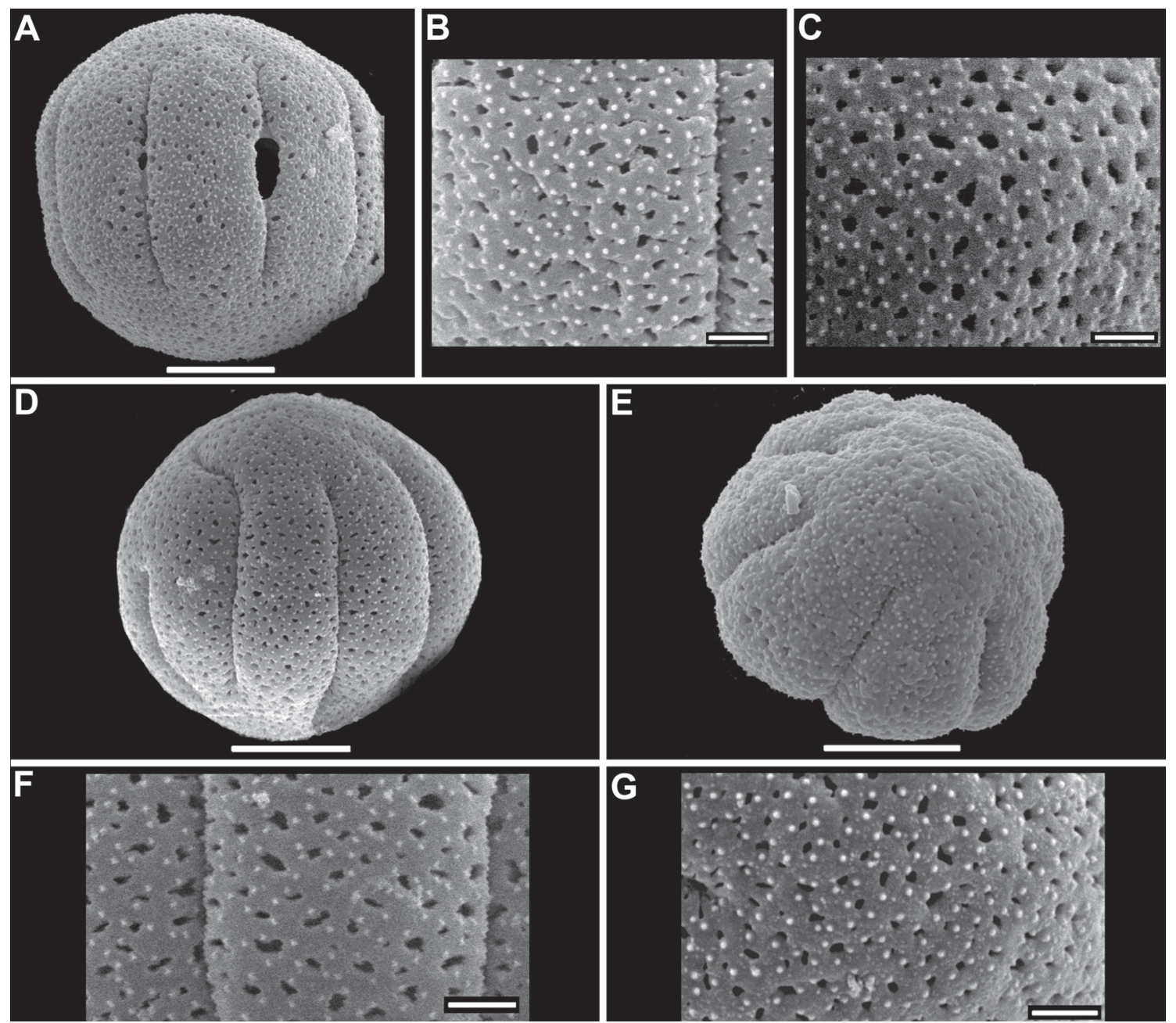

Fig. 3. Microfotografías de polen de Staelia. A-C: Staelia glandulosa. A: Vista ecuatorial. B: Detalle de mesocolpio. C: Detalle de apocolpio. D-G: Staelia harleyi. D. Vista ecuatorial, con uno de los colpos prolongado hacia el apocolpio. E: Vista subpolar. F: Detalle de mesocolpio. G: Detalle de apocolpio. A-C: R.M. Salas \& al. 451 (CTES). D-E: R.M. Salas \& al. 456 (CTES). Escalas A, D, E=10 $\mu \mathrm{m}, \mathrm{B}-\mathrm{C}, \mathrm{F}-\mathrm{G}=2 \mu \mathrm{m}$.

exina microreticulada-reticulada (Fig. 2 H-K) y Anthospermopsis catechosperma (Fig. 2 A-D) perforada-microreticulada. Las perforaciones son circulares o alargadas, oscilan entre $0,1-0,8 \mu \mathrm{m}$ de diámetro, en ocasiones varias de estas confluyen formando lúmenes irregulares de 3-5 $\mu \mathrm{m}$ de largo, su densidad varía entre $26-76$ en $25 \mu \mathrm{m}^{2}$ en los distintos taxones. En S. catolensis, los lúmenes varían de 0,1-1,2 $\mu \mathrm{m}$ de diámetro, los mismos son circulares, alargados o irregulares, levemente mayores y densos en el apocolpio, con muros de
0,4-0,6 $\mu \mathrm{m}$ de ancho (Fig. $2 \mathrm{~J}-\mathrm{K}$ ). Las microespinas son muy pequeñas, varían de 0,1 a $0,2 \mu \mathrm{m}$ y se encuentran en toda la superficie del grano. La densidad de las microespinas varía en las diferentes especies de 46 a 150 por $25 \mu \mathrm{m}^{2}$ (Fig. 2 C-D, J-K; 3 B-C, F-G; 4 C-D, G; 5 C-D, G-H, K-L).

\section{Tessiera}

MO - Los granos de polen de Tessiera son 1214 estefanocolporados, suboblatos, radiosimétricos, isopolares y de ámbito circular. Tamaño grande, con 

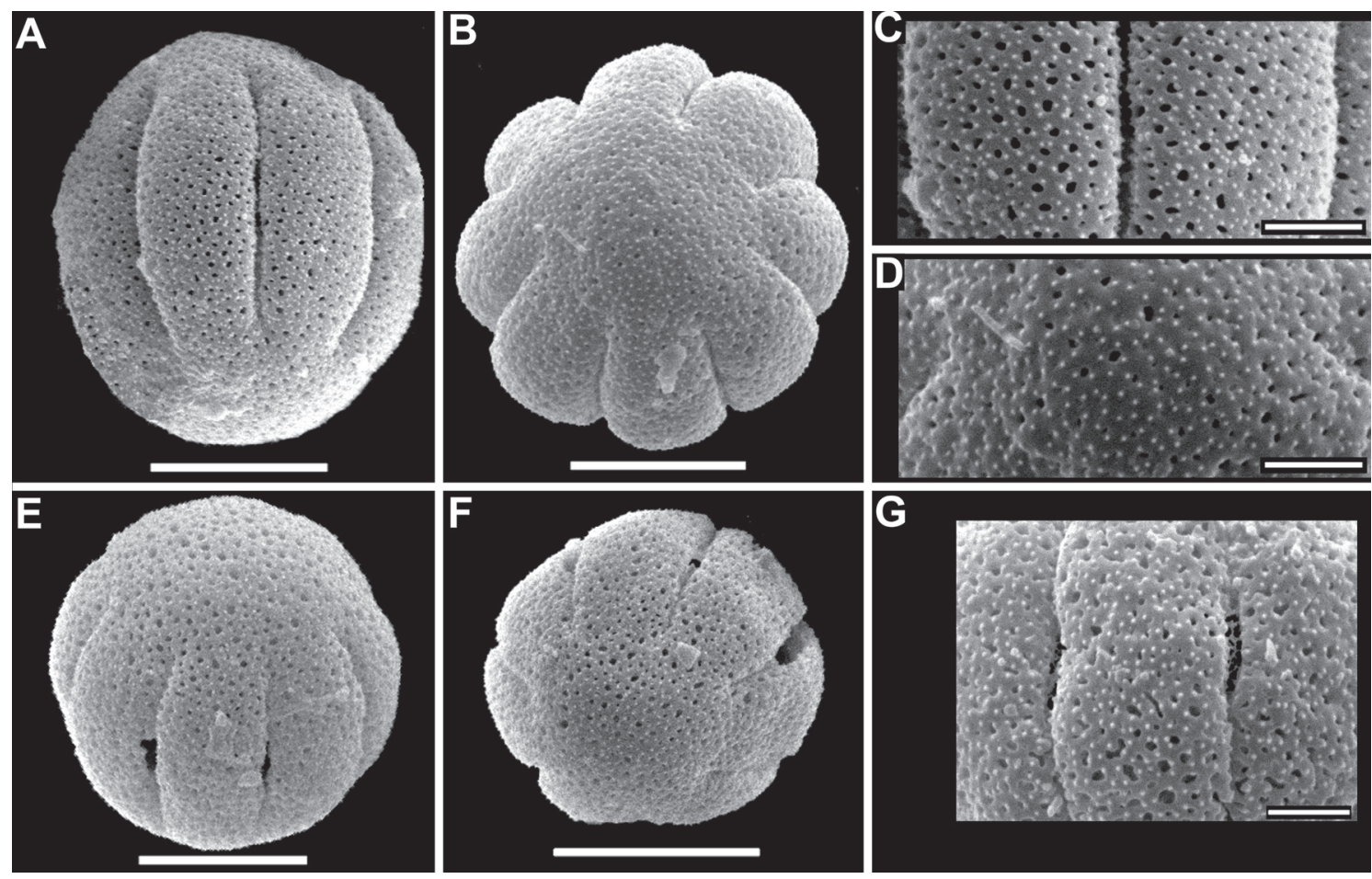

Fig. 4. Microfotografías de polen de Staelia. A-D: Staelia juarezii. A: Vista ecuatorial de grano de polen. B: Vista polar. C: Detalle de mesocolpio. D: Detalle de apocolpio. E-G: Staelia longipedicellata. E: Vista subecuatorial. F: Vista subpolar. G: Detalle de mesocolpio. H-K. A-D: Burkart A. s.n. (SI). E-G: Fuentes A. et al. 684 (CTES). Escalas A-B, E-F=10 $\mu \mathrm{m}, \mathrm{C}-\mathrm{D}, \mathrm{G}=2 \mu \mathrm{m}$.

valores de $\mathrm{P}=58,3-75 \mu \mathrm{m}$ y de $\mathrm{E}=58,8-78,4 \mu \mathrm{m}$. Colpos cortos de $18-21 \mu \mathrm{m}$ de longitud ( $\mathrm{LC} / \mathrm{P}=0,28$ $0,31)$, endoaberturas en endocíngulo. Exina de 2-3 $\mu \mathrm{m}$ de espesor, sexina mayor o igual que la nexina. Exina perforada-microreticulada o microreticuladareticulada, uniformemente microequinada (Fig. 6 L-M).

MEB - Se interpretó a la exina como transicional debido a que se encontraron patrones perforadomicroreticulados o microreticulado-reticulados (Fig. 6 A-D, G-H, J). El primero se encontró en Tessiera lithospermoides, debido que se observaron intercaladas áreas con perforaciones de 0,1-1 $\mu \mathrm{m}$ con otras áreas de lúmenes de 0,5-1,2 $\mu \mathrm{m}$ y muros de 0,2-0,5 $\mu \mathrm{m}$ (Fig. 6 A-D). El segundo tipo es de T. hexasepala, donde se observaron perforaciones de 0,1-1 $\mu \mathrm{m}$, con lúmenes de 1-2,8 $\mu \mathrm{m}$ y muros de 0,18-0,4 $\mu \mathrm{m}$ (Fig. 6 G-H, J). En ambos casos la presencia de perforaciones y lúmenes hace difícil la interpretación de la escultura de la exina. Al igual que el caso de Planaltina, se aplicaron los términos sugeridos por Dessein (2003) y Dessein et al. (2002, 2005b) para granos muy similares, quienes a su vez siguieron la terminología de Punt et al. (1994). En granos rotos se observó un endocíngulo de 10,2-11,47 $\mu \mathrm{m}$, con prolongaciones triangulares (Fig. 6 E, I). Exina de 2,5-2,75 $\mu \mathrm{m}$ de espesor, sexina de 1,2-1,5 $\mu \mathrm{m}$ (tectum $0,3-0,5$ y columelas de 0,9-1 $\mu \mathrm{m}$ ), nexina de 0,8-1 $\mu \mathrm{m}$ (Fig. $6 \mathrm{~F}, \mathrm{~K}$ ). Las perforaciones son subcirculares en el apocolpio o alargadas en el mesocolpio, su densidad no varía entre meso o apocolpio. Las espínulas son muy pequeñas, no superan los $0,2 \mu \mathrm{m}$ y se encuentran uniformemente distribuidas. La densidad de las espínulas no varía entre mesocolpio o apocolpio. Nexina granular con grietas longitudinales (Fig. 6 C-D, F, G-J).

A continuación, se presenta una clave para reconocer los tres tipos polínicos, en el tipo Staelia se incluye a Anthospermopsis. Las diferencias $\mathrm{y}$ afinidades entre los géneros se resumen en las Tablas 1 y 2. 
Bol. Soc. Argent. Bot. 49 (1) 2014

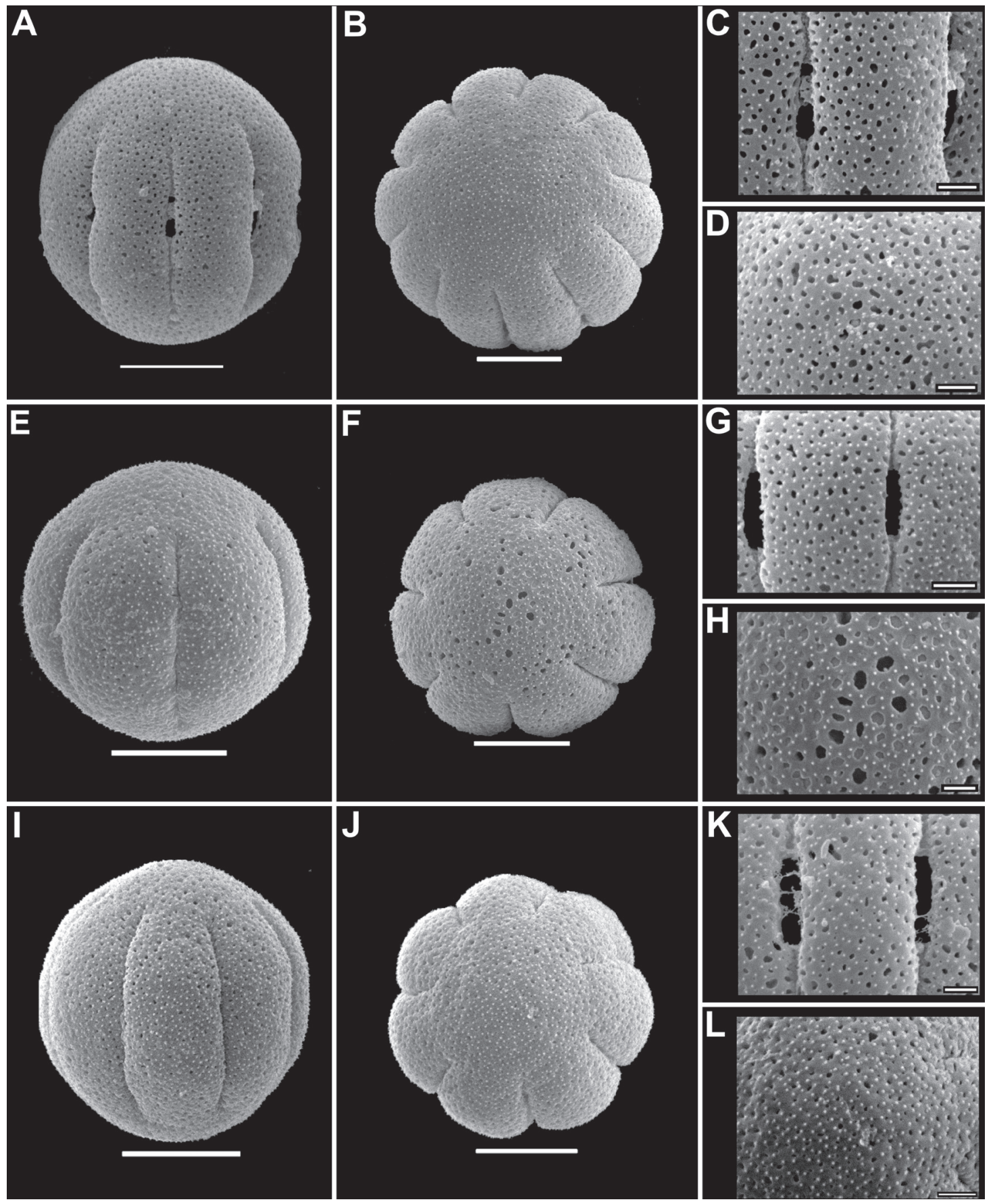

Fig. 5. Microfotografías de polen de Staelia. A-D: Staelia thymoides. A: Vista ecuatorial de grano de polen. B: Vista polar. C: Detalle de mesocolpio. D: Detalle de apocolpio. E-H: Staelia herzogii. E: Vista ecuatorial. F: Vista subpolar. G: Detalle de mesocolpio. H: Detalle de apocolpio. I-L: Staelia virgata. I: Vista ecuatorial. J: Vista polar. K: Detalle de mesocolpio. L: Detalle de apocolpio. A-D: R.M. Salas 380 (CTES). E-H: Irwin H.S. \& al. 33052 (UB). I-L: R.M. Salas 170 (CTES). Escalas A-B, E-F, I-J=10 $\mu \mathrm{m}, \mathrm{C}-\mathrm{D}, \mathrm{G}-\mathrm{H}, \mathrm{K}-\mathrm{L}=2 \mu \mathrm{m}$. 

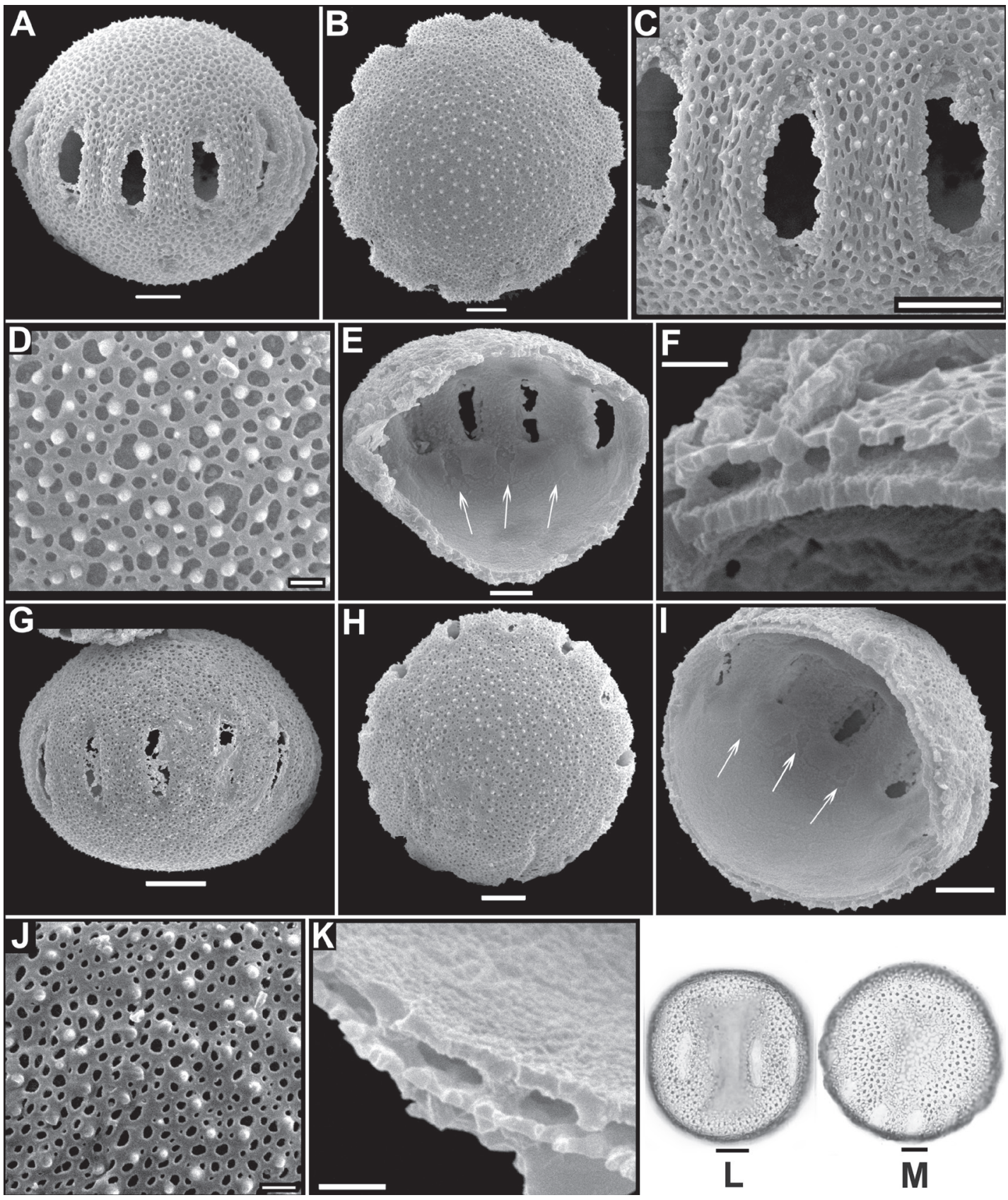

Fig. 6. Microfotografías de polen de Tessiera. A-F: Tessiera hexasepala. A: Vista ecuatorial de grano de polen. B: Vista polar. C: Detalle de mesocolpio. D: Detalle de apocolpio. E: Interior de grano roto, con flechas indicando prolongaciones del endocíngulo a nivel del mesocolpio. F: Exina en grano roto, nótese las microespinas sostenidas por una columela. G-M: Tessiera lithospermoides. G: Vista ecuatorial. H: Vista polar. I: Interior de grano roto, con flechas indicando prolongaciones del endocíngulo a nivel del mesocolpio. J: Detalle de mesocolpio. K: Exina en grano roto. A-F: Elorsa M. 3613 (MEXU). G-M: Soto Núñez J.C. 6850 (MEXU). Escalas A-C, E, G-I, L-M=10 $\mu \mathrm{m}, \mathrm{D}, \mathrm{F}, \mathrm{K}, \mathrm{L}=2 \mu \mathrm{m}$. 
Bol. Soc. Argent. Bot. 49 (1) 2014

Tabla 1. Comparación de los caracteres polínicos de Staelia s.l.

\begin{tabular}{|c|c|c|c|}
\hline Carácter & Planaltina & Staelia & Tessiera \\
\hline Forma & Oblato-esferoidales & Esferoidales, raro suboblatos & Suboblatos \\
\hline Tamaño & Grandes & Pequeños a medianos & Grandes \\
\hline Valor de $P$ y E & $P=42-65$ y $E=50-64,5$ & $P=21-34 \mu m$ y $E=20-30,8$ & $P=58,3-75$ y $E=58,8-78,4 \mu m$ \\
\hline Simetría & Radiosimétricos & Radiosimétricos & Radiosimétricos \\
\hline Ámbito & Circulares & Circulares & Circulares \\
\hline LC/P & $0,22-0,29$ & $0,57-0,77$ & $0,28-0,31$ \\
\hline Número de ECA & $10-11(-13)$ & $7-10$ & $12-14$ \\
\hline Tipo y tamaño de ECA & $\begin{array}{l}\text { Colpos cortos de } 12,5- \\
14,8 \mu \mathrm{m} \text { de largo. }\end{array}$ & $\begin{array}{l}\text { Colpos largos de } 12- \\
21,7 \mu \mathrm{m} \text { de largo. }\end{array}$ & $\begin{array}{l}\text { Colpos cortos de18- } \\
21 \mu \mathrm{m} \text { de largo. }\end{array}$ \\
\hline Tipo y tamaño de ENA & $\begin{array}{l}\text { Endocíngulo de } \\
10,3-11,8 \mu \mathrm{m}\end{array}$ & $\begin{array}{l}\text { Endocíngulo } 3-5 \mu \mathrm{m} \text {, extendido } \\
\text { a } 5-7 \mu \mathrm{m} \text { a nivel de los colpos }\end{array}$ & $\begin{array}{l}\text { Endocíngulo } 10,2-11,47 \mu \mathrm{m} \text {, } \\
\text { extendido en los colpos }\end{array}$ \\
\hline Espesor de exina & $3-5 \mu \mathrm{m}$ & $2,2-3,5 \mu \mathrm{m}$ & $2-3 \mu \mathrm{m}$ \\
\hline Escultura & $\begin{array}{l}\text { Perforada-microreticulada o } \\
\text { microreticulada-reticulada }\end{array}$ & $\begin{array}{l}\text { Comúnmente tectada- } \\
\text { perforada, raro perforada- } \\
\text { microreticulada o } \\
\text { microreticulada-reticulada }\end{array}$ & $\begin{array}{l}\text { Perforada-microreticulada o } \\
\text { microreticulada-reticulada }\end{array}$ \\
\hline Ornamentación & $\begin{array}{l}\text { Uniformemente } \\
\text { microequinados }\end{array}$ & Uniformemente microequinados & $\begin{array}{l}\text { Uniformemente } \\
\text { microequinados }\end{array}$ \\
\hline
\end{tabular}

P: Diámetro polar. E. Diámetro ecuatorial. LC/P: cociente entre longitud del colpo y diámetro polar. ECA: ectoabertura. ENA: endoabertura.

Tabla 2. Resumen de los caracteres polínicos de las especies analizadas de Staelia. s.l.

\begin{tabular}{|c|c|c|c|c|c|c|c|c|}
\hline \multirow[b]{2}{*}{ Taxón } & \multirow[b]{2}{*}{ PxE } & \multirow[b]{2}{*}{ P/E } & \multicolumn{2}{|c|}{ Exina } & \multirow{2}{*}{\multicolumn{2}{|c|}{$\begin{array}{l}\text { Longitud } \\
\text { Colpos }\end{array}$}} & \multirow{2}{*}{$\begin{array}{l}\text { Número } \\
\text { de colpos }\end{array}$} & \multirow[b]{2}{*}{ Escultura } \\
\hline & & & Sexina & Nexina & & & & \\
\hline $\begin{array}{l}\text { Anthospermopsis } \\
\text { catechosperma }\end{array}$ & $25,7 \times 25,3$ & 1,01 & 1,1 & 1,12 & & 15,6 & 7 & $\begin{array}{l}\text { Tectado-perforada } \\
\text { a Microreticulada }\end{array}$ \\
\hline Staelia catolensis & $26,7 \times 25,7$ & 1,05 & 1,1 & 1,2 & & 17,4 & $7(-8)$ & $\begin{array}{l}\text { Microreticulada- } \\
\text { reticulada }\end{array}$ \\
\hline S. glandulosa & $27,2 \times 26,3$ & 1,03 & 1,1 & 0,9 & & 15,6 & $7(-8)$ & Tectado-perforada \\
\hline S. harleyi & $26,9 \times 25,7$ & 1,04 & 1,1 & 0,89 & & 15,3 & $7(-8)$ & Tectado-perforada \\
\hline S. herzogii & $24,6 \times 24,5$ & 1 & 1,66 & 1,15 & & 13,68 & $9-10$ & Tectado-perforada \\
\hline S. juarezii & $24,1 \times 23,8$ & 0,98 & 1,4 & 1,12 & & 11,02 & $7-8$ & Tectado-perforada \\
\hline S. longipedicellata & $22,19 \times 22,08$ & 1 & 1,1 & 0,83 & & 11,27 & 7-8 & Tectado-perforada \\
\hline S. nelidae & $24,5 \times 24,3$ & 1 & 1,27 & 1,12 & & 13,68 & $7-9(-10)$ & Tectado-perforada \\
\hline S. thymoides & $27,9 \times 27$ & 1,06 & 1,385 & 1,04 & & 16 & $7-8$ & Tectado-perforada \\
\hline S. tocantinsiana & $24,5 \times 24,9$ & 0,98 & 1,66 & 1,15 & & 15,6 & 7 & Tectado-perforada \\
\hline S. virgata & $26,9 \times 25,7$ & 1,03 & 1,68 & 1,29 & & 15,04 & $7-10$ & Tectado-perforada \\
\hline \multicolumn{9}{|c|}{ PLANALTINA } \\
\hline Planaltina capitata & $51,2 \times 56,9$ & 0,89 & & 2 & 2,1 & 13,6 & $10-11$ & $\begin{array}{l}\text { Microreticulada- } \\
\text { reticulada }\end{array}$ \\
\hline P. lanigera & $53,6 \times 58,2$ & 0,92 & & 2,2 & 2,3 & 14 & $10(-11)$ & $\begin{array}{l}\text { Perforada- } \\
\text { Microreticulada }\end{array}$ \\
\hline P. myndeliana & $49 \times 56,2$ & 0,87 & & 2,1 & 2,2 & 13,2 & $10(11)$ & $\begin{array}{l}\text { Perforada- } \\
\text { Microreticulada }\end{array}$ \\
\hline \multicolumn{9}{|c|}{ TESSIERA } \\
\hline Tessiera hexasepala & $62,9 \times 68,9$ & 0,92 & & 1,3 & 1,2 & 20,1 & (12-) 13 & $\begin{array}{l}\text { Microreticulada- } \\
\text { reticulada }\end{array}$ \\
\hline T. lithospermoides & $64,4 \times 69,2$ & 9,93 & & 1,2 & 1,3 & 18,9 & $12-14$ & $\begin{array}{l}\text { Perforada- } \\
\text { Microreticulada }\end{array}$ \\
\hline
\end{tabular}

Los datos se presentan en micras. 


\section{R. M. Salas y E. L. Cabral - Morfología polínica de Staelia s.I. (Rubiaceae)}

\section{Clave para diferenciar los géneros en base a caracteres polínicos}

1. Granos de polen pequeños a medianos $(\mathrm{P}=21$ $34 ; \mathrm{E}=20-30,8 \mu \mathrm{m})$, colpos largos $(\mathrm{LC} / \mathrm{P}=0,57$ $0,77)$. Staelia

1. Granos de polen grandes $(\mathrm{P}=42-75 ; \mathrm{E}=50-78,4$ $\mu \mathrm{m})$, colpos cortos $(\mathrm{LC} / \mathrm{P}=0,22-0,32)$.

2. Granos 10-11(-13) colporados. Perforaciones o lúmenes con márgenes espesados. Exina de 3-5 $\mu \mathrm{m}$ de espesor. Planaltina

2. Granos 12-14-colporados. Perforaciones o lúmenes sin márgenes espesados. Exina de 2-3 $\mu \mathrm{m}$. Tessiera

\section{Discusión Y CONCLUSIONES}

Mediante la morfología polínica es posible diferenciar claramente los tres géneros previamente establecidos mediante datos exomorfológicos: Planaltina, Staelia y Tessiera (Salas \& Cabral 2010a, b). Por lo tanto, los resultados palinológicos no apoyan la exclusión de Anthospermopsis de los límites de Staelia realizada por Kirkbride (1997). Dentro de cada taxón la morfología polínica resultó ser muy homogénea, por lo que es posible reconocer un único tipo polínico para cada género. A pesar de esto, se presentan algunas variaciones menores en el tamaño, forma y ornamentación de la exina. A continuación se detallan los aportes de la morfología del polen en cada género. Dentro del género Staelia, unas pocas especies pueden ser diferenciadas fácilmente mediante caracteres polínicos. Por ejemplo, Staelia catolensis es la única especie con exina reticulada. En las demás especies, es posible diferenciar a $S$. juarezii y $S$. longipedicellata por tener granos de menor tamaño (menores de $24 \mu \mathrm{m}$ ). Staelia virgata y $S$. nelidae resultaron las más variables en cuanto al número de aberturas (7-10), mientras que Staelia thymoides presentó granos levemente mayores a las demás (hasta $34 \mu \mathrm{m}$ ). En Planaltina, al igual que en Staelia la variación infragenérica es notoriamente escasa. Las especies se dividieron en dos grupos en base al tipo de escultura. Exina perforadamicroreticulada se encontró en $P$. myndeliana y $P$. lanigera, y microreticulada-reticulada en $P$. capitata. Ambos tipos de esculturas se diferencian únicamente en el diámetro de los lúmenes, 0,1-1,05 $\mu \mathrm{m}$ en $P$. myndeliana y $P$. lanigera y $0,5-2,4 \mu \mathrm{m}$ en P. capitata.

En Tessiera, las especies también se separaron en base al patrón de la exina. Perforadamicroreticulada se encontró en $T$. lithospermoides y microreticulada-reticulada en $T$. hexasepala. En el polen de las especies de Tessiera, se intercalan áreas de perforaciones con microretículo o retículo en un mismo grano, por lo que se determinó que sus especies tienen tipos transicionales. El tipo de $T$. hexasepala tiene lúmenes levemente mayores a los de $T$. lithospermoides, hasta $2,8 \mu \mathrm{m}$ en la primera y hasta $1,2 \mu \mathrm{m}$ en la segunda.

Comparación polínica con otros géneros de las tribus Spermacoceae y Rubieae:

con respecto al polen de Staelia solo se conoce la descripción en cuatro especies (Galati, 1988; Dessein, 2003; Silveira et al., 2012). Sin embargo, se hicieron en el marco de tesis doctorales o bien en floras polínicas regionales. Entre estos autores, Dessein (2003), describió la endoabertura como un endocíngulo, mientras que Galati (1988) y Silveira et al. (2012) como lalongada. En este trabajo, se comprobó que todos los taxones estudiados presentan endocíngulo. Entre las especies americanas de Spermacoceae (sensu Robbrecht, 1988), el polen de Staelia es similar a lo descrito para Emmeorhiza umbellata (Melhem et al., 1974, Jung-Mendaçolli 1984, Pire 1993, Jung-Mendaçolli \& Melhem 1994), con el que comparte colpos largos, el tamaño mediano y la exina microreticulada-reticulada. Melhem et al. (2003) mencionó que la endoabertura de esta especie es lalongada y difusa, mientras que Dessein (2003) realizó una descripción en base a granos rotos y concluyó que al igual que en Staelia, la endoabertura es también un endocíngulo.

Morfología polínica similar a Staelia también se observó en representantes australianos de Spermacoce. Recientemente, Dessein (2003) y Dessein et al. (2005b) describieron cuatro tipos polínicos en especies australianas de Spermacoce. El "tipo 20" descrito por los autores coincide en gran medida con los granos de Staelia, sobre todo el "subtipo 20c". Ellos describen al "tipo 20" como granos 7-17-zonocolporados, pequeños a medianos $(E=19-41,7 \mu \mathrm{m})$, esferoidales o suboblados, de ámbito circular, con colpos largos, endoabertura en endocíngulo (a veces extendido a nivel de los colpos) y dentro de éste separaron al "subtipo 20c" 
por el tectum perforado raramente microreticulado. Esta detallada descripción incluye a los caracteres conocidos para Staelia, incluso las extensiones del endocíngulo a nivel de los colpos. La diferencia más notoria se presenta durante el análisis del endocíngulo bajo MO, ya que es notoriamente visible en las especies australianas de Spermacoce y difuso en las especies de Staelia y Anthospermopsis.

En cuanto a Planaltina, Dessein (2003) estudió el polen de $P$. capitata, sin embargo realizó la descripción bajo Staelia capitata y conjuntamente con otras especies de Staelia s.s., por lo tanto resulta difícil extraer los datos correspondientes a esta especie. El tipo polínico de Planaltina es muy particular en Spermacoceae s.s. de América, no obstante Dessein (2003) y Dessein et al. (2002) reportaron granos de morfología muy similar en representantes africanos. Los autores describieron para Spermacoce de África 11 tipos polínicos basados en el tamaño, tipo, posición, tamaño y número de aberturas y tipo de endoabertura. Entre los tipos descritos, el "tipo 16" incluye parcialmente los caracteres descriptos en el presente trabajo para el tipo Planaltina. Los autores describieron al "tipo 16" como granos 13-18-zonocolporados, oblato u oblato-esferoidales, $E=90-115,5 \mu \mathrm{m}$, de ámbito circular, con colpos cortos y angostos, endoabertura en un ancho endocíngulo y tectum perforado o foveolado. El polen de las especies de Planaltina, presenta algunas diferencias en cuanto al tamaño $(\mathrm{E}=$ 50-64,5 vs $\mathrm{E}=90-115,5 \mu \mathrm{m})$, el número de colpos [10-11(-13) vs 13-18] y la relación LC/P (0,22$0,29$ vs $0,14-24,6 \mu \mathrm{m})$. Sin embargo, comparten el tipo y disposición de ecto y endoaberturas, la exina tectado-perforada, las perforaciones con los bordes espesados y microespinas uniformemente distribuidas en todo el grano.

El polen de Tessiera, al igual que el de Planaltina es muy particular en Spermacoceae s.s. de América. No obstante, Dessein et al. (2002) y Dessein (2003) describieron entre los representantes africanos de Spermacoce granos morfológicamente similares. A diferencia de Planaltina, los granos de Tessiera concuerdan en mayor medida con el "tipo 17", que incluye casi todos los caracteres descritos en este estudio para este género. Dessein et al. (2002), describieron al "tipo 17" como granos de polen 8-16-zonocolporados, suboblatos, raramente oblato-esferoidales, $\mathrm{E}=62-91 \mu \mathrm{m}$, de ámbito circular, con colpos cortos y angostos ( $\mathrm{LC} / \mathrm{P}=0,18$ -
$0,24 \mu \mathrm{m})$, endoabertura en un ancho endocíngulo y tectum perforado o perforado-microreticulado, con grandes perforaciones o lúmenes intercalados con perforaciones pequeñas. El polen de las especies de Tessiera presenta leves diferencias en cuanto al tamaño $(\mathrm{E}=58,8-78,4$ vs $\mathrm{E}=90-115,5 \mu \mathrm{m})$ y $\mathrm{LC} / \mathrm{P}$ (0,22-0,29 vs 0,14-24,6 $\mu \mathrm{m})$.

De acuerdo a Dessein et al., (2005a), el polen multiaperturado es común en linajes herbáceos de la familia, tales como Rubieae y Spermacoceae. En este sentido, los granos de polen de Staelia y Anthospermopsis son morfológicamente similares a los encontrados en géneros de la tribu Rubieae (Asperula, Crucianella, Cruciata, Galium, Rubia y Sherardia). Con estos géneros, Staelia comparte el tamaño (mediano a pequeño), los colpos largos y delgados y el tectum perforado. Sin embargo, difiere sustancialmente en la presencia de endoaberturas, debido a que todas las especies de Staelia presentan invariablemente un endocíngulo, mientras que en Rubieae éste último está ausente en todos los géneros estudiados (Huysmans et al., 2003).

Los tipos polínicos de Planaltina, Staelia y Tessiera permiten diferenciar a estos géneros entre sí y de la mayoría de los representantes americanos de Spermacoceae s.s. Razón por lo cual, se propone a los caracteres polínicos como probables sinapomorfías y a las similitudes, con algunas especies paleotropicales de Spermacoce, como convergencias evolutivas. Los géneros y las especies africanas o australianas de Spermacoce no comparten un ancestro común reciente con los géneros aquí estudiados, siendo además morfológicamente diferentes (Salas, 2012). En cuanto a Staelia, se reconoce además que comparte el tipo polínico con el género monoespecífico Emmeorhiza. Sin embargo, según los aportes moleculares Staelia sería hermano de Psyllocarpus, mientras que Emmeorhiza de Crusea (Kårehed et al., 2008; Salas, 2012).

Los tipos polínicos con los cuales se comparan a las especies aquí estudiadas se describieron inicialmente para especies americanas de Borreria (Pire 1996). Posteriormente, fueron ampliados para incluir representantes africanos y australianos de Spermacoce (Dessein 2003, Dessein et al., 2005b). Dessein et al., (2002) fueron los primeros en aplicar esta clasificación a especies africanas, quienes argumentaron que esto facilitaría su estudio 


\section{R. M. Salas y E. L. Cabral - Morfología polínica de Staelia s.I. (Rubiaceae)}

mediante una terminología común. En este sentido, se plantea la posibilidad de ampliar los tipos polínicos a los géneros aquí estudiados y también a los restantes géneros de Spermacoceae s.s. Esta propuesta facilitaría la comparación entre los distintos géneros mediante tipos polínicos estandarizados. De esta manera, el "tipo 20" está presente en Emmeorhiza, Staelia y algunas especies de Spermacoce australianas. Mientras que Planaltina y Tessiera, compartirían "los tipos 16 y 17" respectivamente con especies africanas de Spermacoce. Otro ejemplo que soporta esta propuesta es el "tipo 1", que se encuentra en especies africanas, americanas, australianas y asiáticas de Spermacoce, en especies americanas de Borreria y en todas las especies de Psyllocarpus secc. Psyllocarpus (Dessein et al., 2002).

\section{Agradecimientos}

A Stella Maris Pire por la formación polínica en las primeras etapas del primer autor. Se agradece también a los curadores de los herbarios mencionados. A SGCyT-UNNE y CONICET por las becas de grado y posgrado otorgadas al primer autor, y a ambas instituciones por los subsidios otorgados a través de los siguientes proyectos: PI-UNNE F003 y PIP 112-200801-02196/09 respectivamente. A los revisores y editores quienes mejoraron notablemente la versión final del manuscrito

\section{Bibliografía}

ANDERSSON, L. 1992. A provisional checklist of Neotropical Rubiaceae. Scripta Bot. Belg. 1: 1-195.

BACIGALUPO, N. M. \& E. L. Cabral. 1996. Infrageneric classification of Borreria (Rubiaceae-Spermacoceae) on the basis of American species. In: E. Robbrecht, C. Puff \& E. Smets (ed.), 2nd Int. Rubiaceae Conf. Meise 1995. Proc., pp. 297-308. Opera Bot. Belg. 7. Natl. Bot. Gard. Belgium, Meise.

BREMEKAMP, C. E. B. 1952. The African species of Oldenlandia L. sensu Hiern \& K. Schumann. Verh. Kon. Ned. Akad. Wetensch., Afd. Natuurk., Sect. 2. 48: 1-297.

CABRAL, E. L. 1985. Valor taxonómico del polen de las especies argentinas del género Borreria (RubiaceaeSpermacoceae). Bol. Soc. Argent. Bot. 24: 169-178.

CABRAL, E. L. 1991. Rehabilitación del género
Galianthe (Rubiaceae). Bol. Soc. Argent. Bot. 27: 235-249.

CABRAL, E. L. \& N. M. BACIGALUPO. 2001a. Scandentia, nuevo género de RubiaceaeSpermacoceae. Darwiniana 39: 29-41.

CABRAL, E. L. \& N. M. BACIGALUPO 2001b. Denscantia, nuevo nombre en reemplazo de Scandentia (Rubiaceae-Spermacoceae). Darwiniana 39: 353.

CANDOLLE, A. P. 1830. Spermacoceae. Prodromus 4: 538-578. Treuttel \& Würtz, Parisiis.

CHAMISSO, L. A. \& D. F. L. SCHLECHTENDAL. 1828. De plantis in expeditione speculatoria Romanzoffiana observatis. Linnaea 3: 364, t. 3. f. 3.

DESSEIN, S. 2003. Systematic Studies in the Spermacoceae (Rubiaceae). Tesis Doctoral, Katholieke Universiteit Leuven. Leuven, Belgium.

DESSEIN, S., S. HUYSMANS, R. ROBBRECHT \& E. SMETS. 2002. Pollen of African Spermacoce species (Rubiaceae). Morphology and evolutionary aspects. Grana 41: 69-89.

DESSEIN, S., S. NTORE, E. ROBBRECHT \& E. SMETS. 2003. Pollen and seeds reveal that Spermacoce thymoidea s.l. (African Rubiaceae, Spermacoceae) represents three endemic or disjunct species from the Zambezian High Plateaus. Syst. Bot. 28: 130-144.

DESSEIN, S., R. HARWOOD, E. SMETS \& E. ROBBRECHT. 2005a. Pollen of the Spermacoce (Rubiaceae) species from the Northern Territory of Australia: morphology and taxonomic significance. Austral. Syst. Bot. 18: 367-382.

DESSEIN, S., H. OCHOTERENA, P. DE BLOCK, F. LENS, E. ROBBRECHT, P. SCHOLS, E. SMETS, S. VINCKIER \& S. HUYSMANS. 2005b. Palynological characters and their phylogenetic signal in Rubiaceae. Bot. Rev. 71: 354-414.

ERDTMAN, C. 1966. Pollen morphology and plant taxonomy-Angiosperms (An introduction to palynology), revised edition. Hafner Publishing Co., New York \& London.

GALATI, B. G. 1988. Estudios embriológicos en la tribu Spermacoceae (Rubiaceae). Tesis Doctoral, Universidad de Buenos Aires. Buenos Aires, Argentina.

HUYSMANS, S., S. DESSEIN, E. SMETS \& E. ROBBRECHT. 2003. Pollen morphology of NW European representatives concerns monophyly of Rubieae (Rubiaceae). Rev. Palaeobot. Palynol. 127: 219-240.

JUNG-MENDAÇOLLI, S. L. 1984. Contribuição ao estudo palinológico das Rubiaceae. Tesis Doctoral, Universidade de São Paulo. São Paulo, Brasil.

JUNG-MENDAÇOLLI, S. L. \& T. S. MELHEM. 1994. Flora polínica da reserva do parque estadual das 
fontes do Ipiranga (São Paulo, Brasil). Hoehnea 21: 131-155.

KÅREHED, J., I. GROENINCKX, S. DESSEIN, T.J. MOTLEY \& B. BREMER. 2008. The phylogenetic utility of chloroplast and nuclear DNA regions and the phylogeny of the Rubiaceae tribe Spermacoceae. Molec. Phylogen. Evol. 49: 843-866.

KIRKBRIDE, J. H. 1997. Manipulus rubiacearum VI. Brittonia 49: 354-379.

MELHEM, T. S., C. L. B. ROSSI \& M. S. F. SILVESTRE. 1974. Pollen morphological studies on Rubiaceae. Hoehnea 1: 153-158.

MELHEM, T. S, M. A. V. CRUZ BARROS, M. S. CORRÊA, H. MAKINO-WATANABE, M. S. F. SILVESTRE-CAPELATO \& V. L. G. ESTEVES. 2003. Variabilidade polínica em plantas de Campos de Jordão (São Paulo, Brasil). Bol. Inst. Bot. 16: 64-69.

PIRE, S. M. 1993. Palynology of the tribe Spermacoceae (Rubiaceae). International Conference the Systemtics of the Rubiaceae 1993. St. Louis, EE.UU.

PIRE, S. M. 1996. Palynological study of American species of Borreria. In: E. Robbrecht, C. Puff \& E. Smets (ed.), 2nd Int. Rubiaceae Conf. Meise 1995. Proc., pp. 413-423. Opera Bot. Belg. 7. Natl. Bot. Gard. Belgium, Meise.

PIRE, S. M. 1997. Género Galianthe subg. Ebelia (Rubiaceae, Spermacoceae): Estudio palinológico. Ann. Missouri Bot. Gard. 84: 878-887.

PIRE, S. M. \& E. L. CABRAL. 1992. El valor del polen en la revalidación de Galianthe (SpermacoceaeRubiaceae). Darwiniana 31: 1-10.

PUNT, W., P. P. HOEN, S. BLACKMORE \& A. LE THOMAS. 2007. Glossary of pollen spore terminology. Rev. Palaeobot. Palynol. 143: 1-81.

ROBBRECHT, E. 1988. Tropical woody Rubiaceae. Characteristic features and progressions. Contributions to a new subfamilial classification. Opera Bot. Belg. 1: 1-271.

SALAS, R. M. 2012. Revisión de Staelia s.l. (Rubiaceae). Tesis Doctoral. Universidad Nacional del Nordeste. Corrientes, Argentina.

SALAS, R. M. \& E. L. CABRAL. 2006a. Una nueva especie y una nueva combinación en el género Staelia (Rubiaceae-Spermacoceae) de Bolivia. Darwiniana 44: 500-503.

SALAS, R. M. \& E. L. CABRAL. 2006b. Una nueva especie del género Staelia (Rubiaceae) para la flora de Brasil. Revista Biol. Neotrop. 3: 1-3.

SALAS, R. M. \& E. L. CABRAL. 2010a. Rehabilitación y lectotipificación del género Tessiera, su relación con Diphragmus y Staelia (Rubiaceae, Spermacoceae): una nueva combinación y un nuevo sinónimo. J. Bot. Res. Inst. Texas 4: 183-194.

SALAS, R. M. \& E. L. CABRAL. 2010b. Planaltina, nuevo género de la tribu Spermacoceae (Rubiaceae) endémico del Planalto Central de Brasil y una nueva especie del estado de Goiás, Brasil. J. Bot. Res. Inst. Texas 4: 195-208.

SALAS, R. M. \& E. L. CABRAL. 2010c. The species of the genus Staelia (Rubiaceae) from Paraguay, a new species and new synonym. Blumea 55: 123-128.

SALAS, R. M. \& E. L. CABRAL. 2011a. Dos especies nuevas de Staelia con hojas ternadas de Brasil. Brittonia 63: 355-364.

SALAS, R. M. \& E. L. CABRAL. 2011b. Staelia culcita (Rubiaceae), a new species from Minas Gerais, Brazil. Pl. Ecol. Evol. 144: 372-376.

SALAS, R. M. \& E. L. CABRAL. 2012a. Staelia catolensis (Rubiaceae), una nueva especie de Catolés, Bahia, Brasil. Novon 22: 82-86.

SALAS, R. M. \& E. L. CABRAL. 2012b. Two new shrubby species of the genus Staelia (Rubiaceae) from Serra do Curral Frio, Bahia, Brazil. Syst. Bot. 37: 507-515.

SCHUMANN, K. M. 1888. Rubiaceae. In: C.F.P. von Martius, Eichler A.G. \& I. Urban (eds). Flora Brasiliensis 6: 1-124. Fleisher, Leipzig.

SILVEIRA, C. E. A. Jr., M. D. Saba \& J. G. Jardim. 2012. Pollen morphology of Rubiaceae Juss. species occurring in an area of caatinga (dryland) vegetation in Bahia State, Brazil. Acta Bot. Bras. 26: 444-455.

SOUZA, E. B. 2008. Estudos sistemáticos em Mitracarpus (Rubiaceae-Spermacoceae), com ênfase em espécies brasileiras. Tesis Doctoral. Universidade Estadual de Feira de Santana, Feira de Santana, Bahia, Brasil.

STANDLEY, P. C. 1931. Staelia scabra. Publ. Field Mus. Nat. Hist., Bot. Ser. 3: 385-386.

VERDCOURT, B. 1958. Remarks on the classification of the Rubiaceae. Bull. Jard. Bot. État Bruxelles 28: 209-290.

Recibido el 27 de mayo de 2013, aceptado el 24 de noviembre de 2013 


\section{R. M. Salas y E. L. Cabral - Morfología polínica de Staelia s.I. (Rubiaceae)}

\section{ApÉNDICE}

Material examinado de Staelia s.l. para los estudios palinológicos. Planaltina capitata. Brasil, Goiás, G. Hatschbach \& J.M. Silva 60036 (CTES). P. lanigera. Brasil, Minas Gerais, Serra do Cabral, M. Hatschbach et al., 64238 (CTES). P. myndeliana. Brasil, Goias, São João da Aliança, G. Hatschbach \& J.M. Silva 60266 (CTES). Anthospermopsis catechosperma Brasil, Bahia, Pilão Arcado, R.M. Salas et al., 440 (CTES); ídem, Barra, Ibiraba, R.M. Salas et al., 427 (CTES). Staelia catolensis. Brasil, Bahia, Catolés, W. Ganev 519 (HUEFS). S. glandulosa Brasil, Bahia, Umburanas, Serra do Curral Frio, R.M. Salas et al., 451 (CTES). S. harleyi. Brasil, Bahia, Umburanas, Serra do Curral Frio, R.M. Salas et al., 456 (CTES). S. hatschbachii. Brasil, Minas Gerais, Grão Mogol, H.S. Irwin 23381 (CTES). S. herzogii. Brasil, Goiás, Parque Nacional Chapada dos Veadeiros, H.S. Irwin et al., 3052 (UB). S. juarezii. Argentina, Formosa, Matacos, Ingeniero Juárez, A. Burkart et al., s.n.(SI). S. longipedicellata. Bolivia, Santa Cruz, Arenales de Guanaco, A. Fuentes et al., 684 (CTES). S. nelidae. Paraguay, Boquerón, entre 4 de mayo y Capitán Lagerenza, F. Mereles 2663 (CTES). S. paganuccii. Brasil, Bahia, Formosa do Río Preto, L.P. Queiroz et al., 14441 (CTES). S. thymoides. Argentina, San Ignacio, Teyú Cuaré, R.M. Salas 380 (CTES). S. tocantinsiana. Brasil, Tocantins, Ilha do Bananal, Parque Nacional do Araguaia, M. A. da Silva et al., 4091 (CTES). S. virgata. Argentina, Corrientes, Riachuelo, R.M. Salas 170 (CTES); ídem, Jujuy, Lozano, Mirador de la Difunta Correa, R.M. Salas 194 (CTES). Tessiera hexasepala. México, Oaxaca, M. Elorsa 3613 (MEXU). T. lithospermoides. México, Guerrero, J.C. Soto Núñez 6850 (MEXU). 
